\title{
Incomplete Faraday cage effect of helicopters used in platform live-line maintenance
}

\author{
G.W.Cameron \\ P.S.Bodger \\ J.J.Woudberg
}

Indexing terms: Helicopters, Live line maintenance, High voltage, Faraday cage

\begin{abstract}
The use of helicopters for maintenance on live overhead transmission lines has become a realistic option. The helicopter blades, body and working platform can be seen as creating an incomplete Faraday cage, which may be an enhancement to live-line worker safety. This paper simulates the condition using a Faraday cage which can be dismantled, in a controlled laboratory environment to ascertain the effectiveness of apparatus.
\end{abstract}

\section{Introduction}

Helicopters have been used for many years in the construction and maintenance of all types of overhead lines, particularly high voltage transmission lines. They are a readily accepted 'tool' in the line maintenance and construction industry, for patrols, inspections, providing rapid access to remote locations for emergency repairs and for lifting equipment. The relationship between the helicopter and the engineer in relation to overhead line construction is specifically outlined in [1]. The purpose of this paper was to address the roles for which the helicopter is appropriate and the reasons for its use. Eskom became the first power utility in the world to have in-house airmobile live-line teams [2].

The maintenance and repair of high voltage transmission systems have historically used hot stick and bare hand methods for energised conditions [3]. Helicopter use to assist with live-line work is a relatively recent innovation. The growing popularity of this work method in some countries reflects the high productivities that can be achieved. They offer an attractive and economic solution to some difficult maintenance problems for which no other viable method is available.

The use of contractor-provided helicopter-airborne services as a replacement for some of the conventional work methods that would typically have been used on an optical ground wire retrofit programme are outlined in [4]. In New Zealand, the introduction of live-line maintenance techniques began with the reinsulation of the interisland HVDC transmission line [5]. This pro-

(C) IEE, 1998

IEE Proceedings online no. 19981787

Paper first received 8th July and in revised form 10th November 1997 The authors are with the Department of Electrical and Electronic Engineering, University of Canterbury, Christchurch, New Zealand vided an economical and technical solution to address high-voltage transmission lines travelling over rugged mountainous areas with very poor ground access.

The codes of practice which facilitate the tasks of linemen performing live-line maintenance using helicopters is covered in [6]. The aim was to be able to achieve a greater safety level for them compared to traditional modes of work. A similar code of practice was prepared for the New Zealand industry when live-line techniques were first introduced in anticipation of helicopter use [7].

Although helicopters have been used to work on energised, overhead AC transmission lines for several years, there has been very little prior use on DC lines [8]. Tests have been carried out at the Manitoba HVDC Research Centre test site at Lundar to ensure that work could be performed safely on DC lines. Field strengths and ion current densities were measured while hovering the helicopter in the vicinity of or bonded onto the HVDC conductors. The tests showed that a helicopter-airborne platform could work effectively close to or bonded to energised DC conductors and could therefore safely be used to perform work on HVDC live-lines.

Of particular interest were observations that the helicopter formed a shielded space between the work platform and the rotors from vertical electrical fields, but provided less shielding from horizontal electrical fields. Rotor downdraught would further reduce the ion densities in the work area.

A discussion to this paper [8] questioned that from an electrical point of view, the rapidly rotating blades appear as a solid disc rather than individual long protrusions with sharp edges. This means that a worker working off the side of a helicopter is effectively surrounded on three sides (top, back and bottom) by metal 'walls', the blades, the helicopter cabin and the work platform, all of which are at the same voltage. This suggests that the worker can be considered to be sitting in an 'incomplete Faraday cage'. This idea was associated with that of rotor downdraught to reduce the ion densities in the work area.

This paper investigates the phenomenon of the 'incomplete Faraday cage' under AC voltage conditions, in an attempt to quantify its effectiveness. A controlled laboratory environment is used so that changes in the electric field profiles could be reliably attributed to changes in the Faraday cage structure and not some atmospheric variation. 


\section{Incomplete Faraday cage}

To investigate the idea that the blades, cabin and the work platform form an 'incomplete Faraday cage' a high voltage laboratory Faraday cage was used [9]. The Faraday cage had the dimensions of $1.5 \mathrm{~m}$ width, $1.5 \mathrm{~m}$ depth and $1.8 \mathrm{~m}$ height. These dimensions are similar to that of a helicopter with platform and thus made a useful simulation tool. It had detachable walls so that front and sides could be progressively removed. The cage was mounted on porcelain insulators to isolate it from earth. Outside the cage the proximity of this earth was expected to influence the actual electric field magnitudes measured. However, changes in electric field patterns could be attributed to the structural changes in the cage when all other factors remained constant.

The grid setup for measuring the electric field and also the equipment required is shown in Figs. 1 and 2. To make electric measurements, a Fluke 45 standard multimeter and a high impedance resistive divider, developed in the High Voltage Laboratory at the University of Canterbury, with a step-down ratio of 10 $000: 1$ was used. The low voltage side of the divider was bonded to the Faraday cage. The design and use of the divider was such that capacitive coupling to the divider string has little influence on the resultant measurement. The high voltage connection becomes a point probe and was used for measuring the electric field magnitude in the air relative to the Faraday cage. An accuracy of $1 \%$ is estimated for the divider.

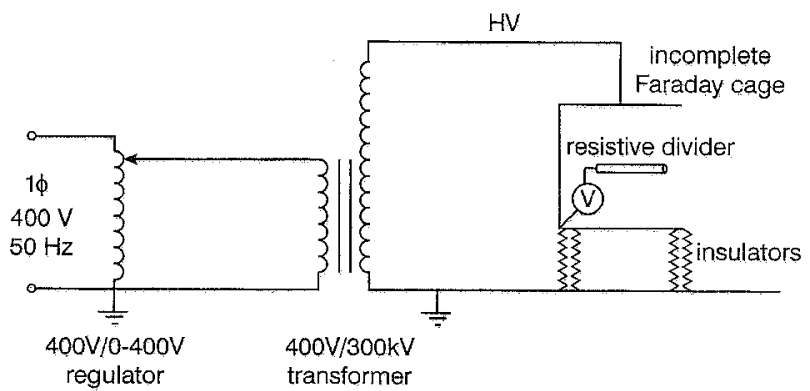

Fig. 1 Experimental and measuring circuit

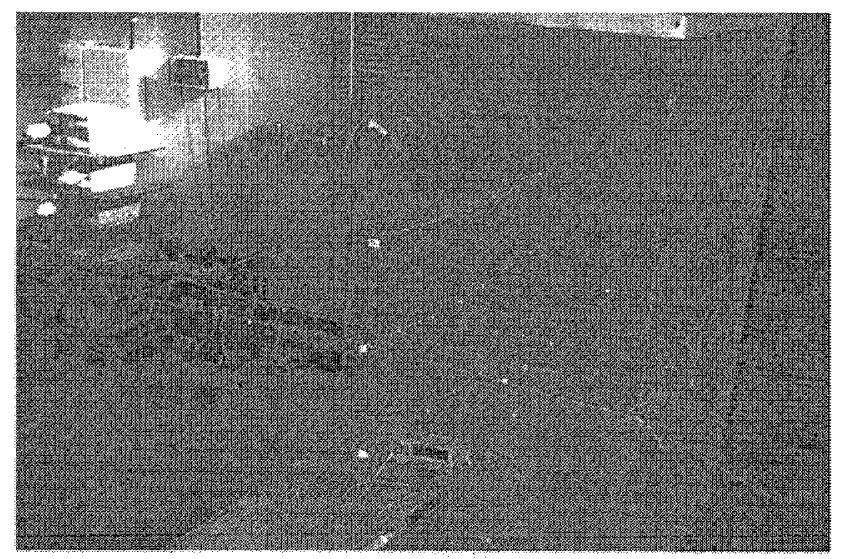

Fig.2 Setup of Faraday cage showing measurement grid

Only points inside and relatively close to the cage were monitored to minimise the proximity effect of the laboratory ground plane. Also, measurements were made by personnel wearing a Faraday live-line suit, within the cage. To minimise this influence on electric field magnitudes, the person stood at the rear, up against the metal back of the cage.
The experimental and measuring circuits are shown in Fig. 1. Because the Faraday cage is effectively isolated from earth, there is no significant current flow and hence no magnetic field effects. Only the electric field voltages are measured. A string grid was erected to provide accurate location of points within the Faraday cage boundaries. This is shown in Fig. 2. The grid provided point measurements in both vertical and horizontal planes through the middle of the cage.

To simulate the incomplete Faraday cage effect, the sides of the cage were individually removed and the results recorded. With only the top, bottom and back panels of the cage left, simulation of a helicopter with platform could be made and the effect of the incomplete Faraday cage could now be measured.

To make the effect comparable to actual voltages encountered in real live-line work, a phase to ground voltage of $127 \mathrm{kV}$ was applied to the cage. This corresponds to an $\mathrm{AC}$ line-to-line voltage of $220 \mathrm{kV}$, the highest transmission voltage used in New Zealand.

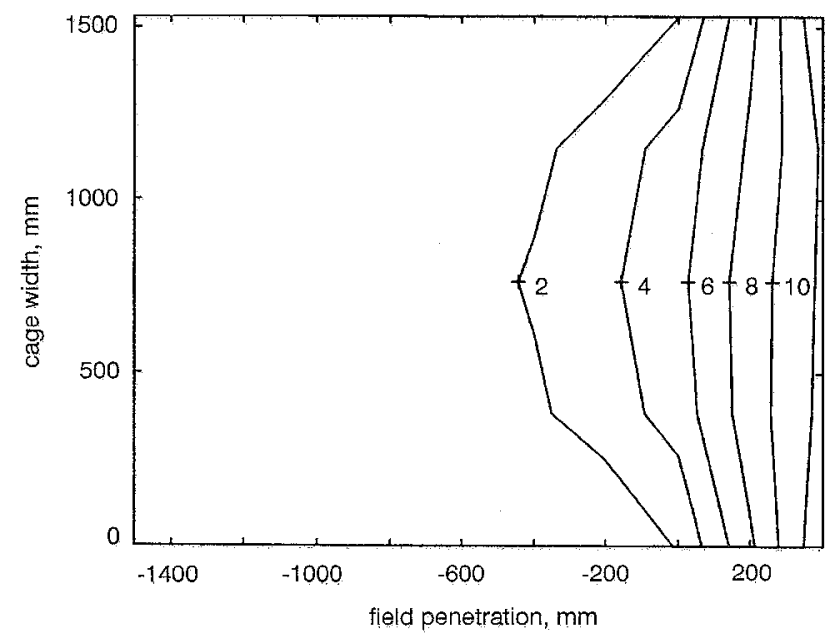

Fig.3 Plan view of cage with front face removed Equipotentials in \%

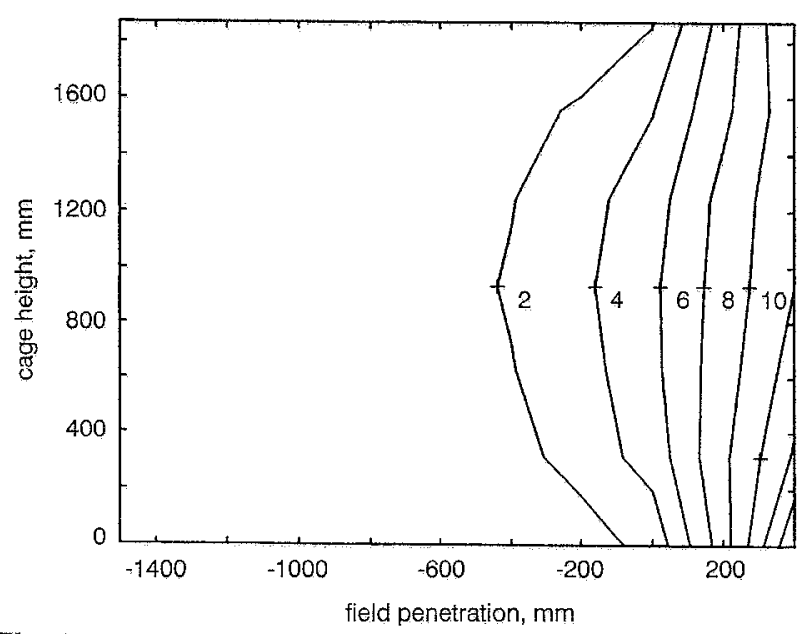

Fig. 4 Side view of cage with front face removed Equipotentials in \%

\section{Results}

The equipotential lines for the plan and side elevation views of the cage with just the front face removed is shown in Figs. 3 and 4. These were taken at the centre of the side and plan views respectively. The electric field penetrates into the cage. This is symmetric about the cage centre where the greatest voltage differences 
were measured. At a depth of $400 \mathrm{~mm}$ into the cage, the value of the equipotential is $2 \%$ of the applied voltage. At the front edge of the cage, the value is approximately $5 \%$. At the edges, the metal of the cage reduces the electric field to zero.

Outside the cage there is an increase in voltage relative to the cage of $12 \%$ within $400 \mathrm{~mm}$. This indicates a dangerous condition for workers outside the cage and suggests hot stick work unless a worker was in a Faraday suit. The asymmetry of the equipotentials shown in Fig. 4 is due to the laboratory ground plane proximity.

Thus, despite the removal of the entire front face of the cage, there is very little penetration of the electric field into the cage interior. This could be a useful working environment for live-line workers, even without protective suits.

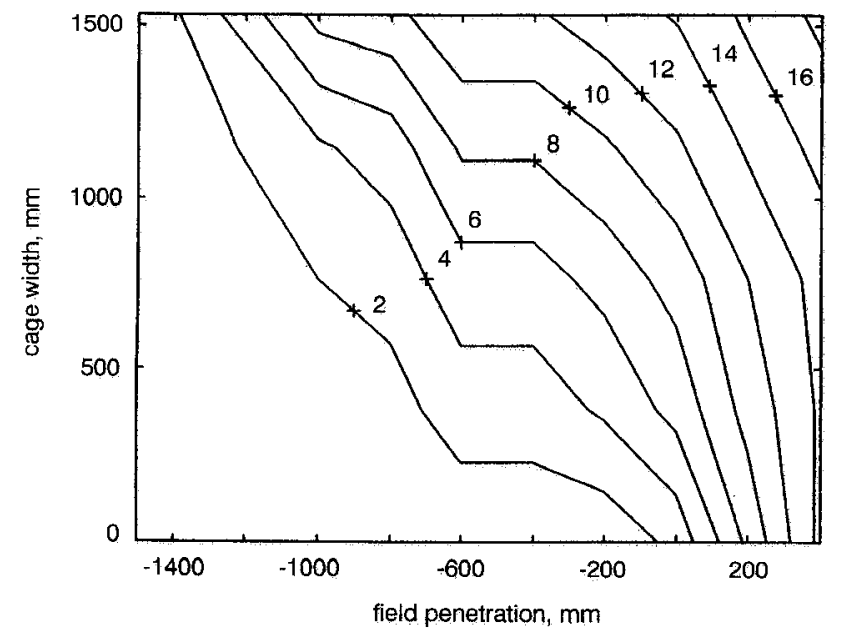

Fig.5 Plan view of cage with front and side removed Equipotentials in \%

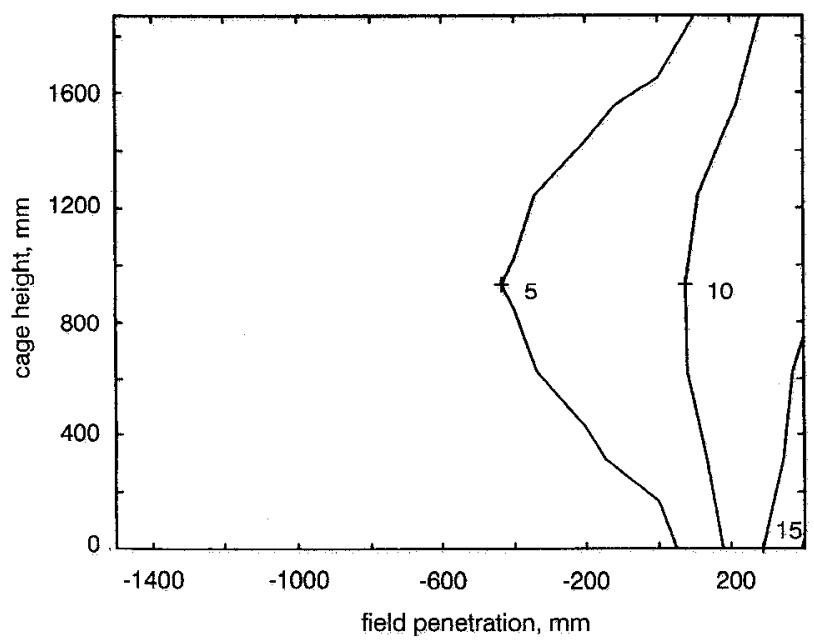

Fig.6 Side view of cage with front and side removed Equipotentials in \%

The plan and side elevation views of the cage with the front face and one side removed are shown in Figs. 5 and 6. From Fig. 5, on the side of the cage that is removed, the electric field magnitudes are larger than those at the remaining side. The electric field has penetrated further into the cage on the removed side leading to a distorted field. The values of field suggest that additional protection in the form of a suit would be necessary for this situation. Fig. 6 shows that the field is still impinging in a circular radial manner in a verti- cal direction, with increased values over those observed in Fig. 4.

In Figs. 7 and 8 the plan and side elevation views of the cage with the front face and both sides removed are shown. From Fig. 7, the field penetrates across the inside of the cage in a circular radial manner opposite to that of how the field initially intruded in Fig. 4. This is due to the removal of the sides as zero equipotentials. The lower electric field values in the centre are due to the bottom ('platform') and the top ('rotor blades'). The value of the electric field at the centre front edge of the cage is approximately $13 \%$. This is significantly higher than when both sides are absent but it is still a small percentage of the applied voltage. Fig. 7 also shows that the field has a value of $5 \%$ at $800 \mathrm{~mm}$ into the cage.

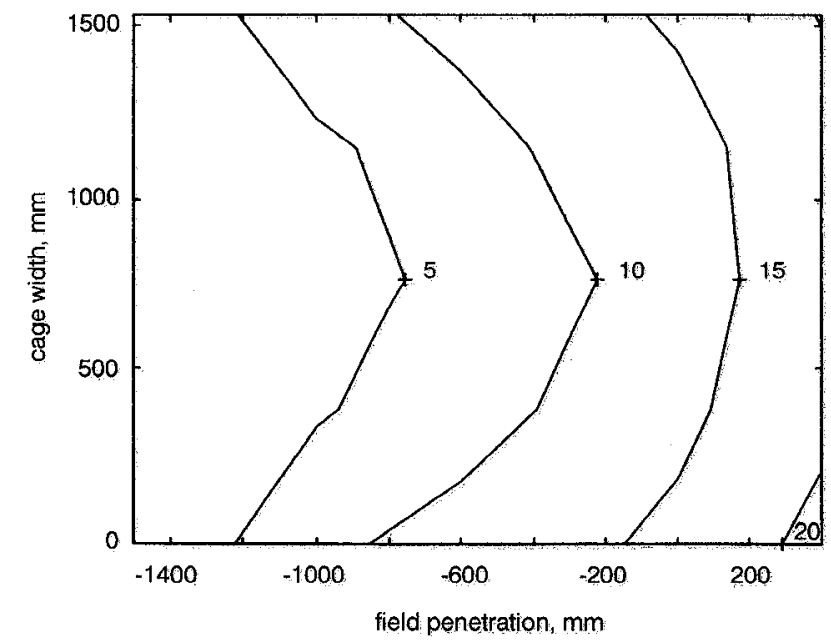

Fig.7 Plan view of cage with front and two sides removed Equipotentials in $\%$

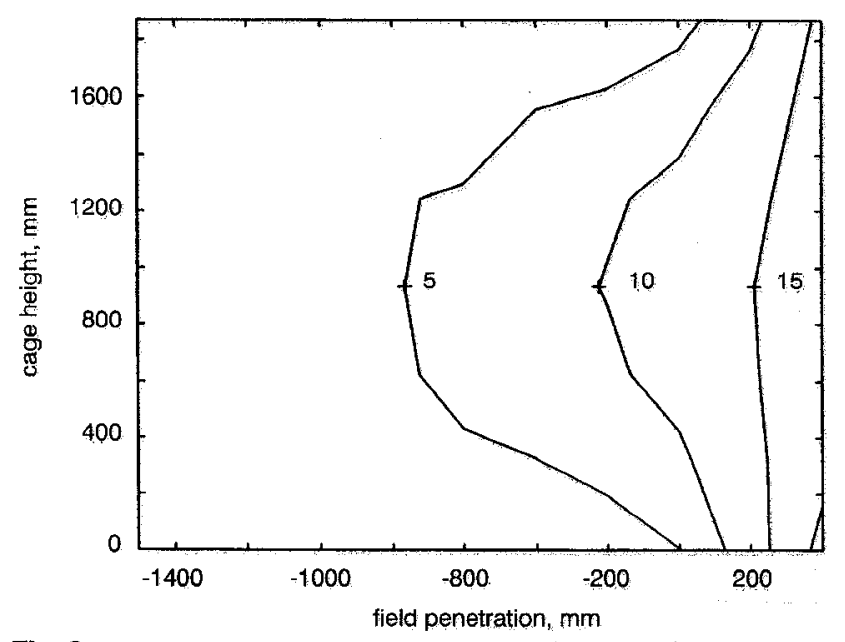

Fig.8 Side view of cage with front and two sides removed Equipotentials in \%

The equipotential profile from top to bottom in Fig. 8 is similar to what has been measured before, but with increased values. The maximum voltage at the centre front of the cage is $16.5 \mathrm{kV}$ (relative to the cage) when the cage is actually at a potential of $127 \mathrm{kV}$ single phase. This shows that although the cage does allow the field to penetrate, the voltage levels are low enough to conclude that an 'incomplete Faraday cage' does have a significant effect on the voltage levels around the live-line worker. 


\section{Conclusions}

The use of helicopters for live-line maintenance has become a realistic option. When using a plafform technique, an incomplete Faraday cage effect, between the rotor blades, helicopter body and working platform, has been proposed. In a simulation of this arrangement under $\mathrm{AC}$ conditions, tests using a partially dismantled laboratory Faraday cage showed that the electric field penetrates into the cage when one or more sides are removed. However, the voltage levels relative to the cage are low enough to conclude that there is an 'incomplete Faraday cage' effect. This has a significant effect on the voltage levels around the live-line worker. A platform with an open front may be sufficient for workers to be protected under live conditions when using hotstick operations.

\section{References}

1 ACKERMANN, R.H., and MORTON, R.J.: "The use of helicopters for live line work by Eskom'. 5th international conference on Transmission and distribution construction and live-line maintenance, Toronto, Canada, June 1990, pp. 111-113
2. BUCHHOLZ, F.C.: 'Helicopter application in transmission systerm maintenance and repair'. IEEE/CSEE joint conference on High voltage transmission systems in China, Beijing, China, October 1987, pp. 472-478

3 BROWNE, N.W., and ADAM, J.F.: 'Construction of lines using helicopters'. IEE international conference on Overhead line design and construction: theory and practice (up to $150 \mathrm{kV}$ ), London, 1988, pp. 202-206 (Conference publication 297)

4 MIZE, D.E. 'Helicopter installation of fibreoptic groundwire on overhead lines'. 6th international conference on Transmission and distribution construction and live-line maintenance, Las Vegas, September 1993, pp. 68-73

5 FORGIE, GC, FREEMAN L.HE and WILLIAMS BA. "The introduction of bare hand line techniques for reinsulation of the New Zealand HVDC inter island link'. 5th international conference on Transmission and distribution construction and live-line maintenance, Toronto, Canada, June 1990, pp. 145-148

6 DE PARNY, R.: 'Helicopter airborne services live line work'. 6th international conference on Transmission and distribution construction and live line maintenance, Las Vegas, September 1993, pp. $74-87$

7 BODGER, P.S.: 'Code of practice for bare-handed live-line maintenance'. Canterprise, University of Canterbury, Christchurch, New Zealand, Dec. 1989

8 HARRIS, E.L., RINDAIL, B.D TARKO, N J and NORRISELYE, O.C.: 'The effect of a helicopter on DC fields and ions', IEEE Trans. Power Deliv., October 1993, 8, (4), pp. 1837-1841

9 BODGER, P.S., and WOUDBERG, J.J.: 'High voltage live-line maintenance laboratory', Int. J. Elect. Eng. Educ., 1994, 31, (3), pp. $195-205$ 